\title{
Beschreibung einer neuen Crabronide aus Paraguay.
}

Von C. Schrottky, Encarnación (Paraguay), nebst Bemerkungen zu ihrer Biologie von A. W. Bertoni.

\section{Xylocrabro umbrosus n. sp.}

․ Schwarz mit gelben Zeichnungen; diese nehmen ein: den Fühlerschaft, das Pronotum, die Calli humerales, an der Basis des Scutellum jederseits ein Fleckchen, das Metanotum (Postscutellum), 2 nahe beisammen stehende Flecke an der Basis des Mittelsegments, je eine Querbinde in der Mitte des zweiten und vierten und nahe am Hinterrande des fünften Tergites, jederseits einen kleinen Fleck auf dem ersten und dritten Tergite, die Aufsenseiten der Tibien aller Beinpaare. Die Tegulae und Tarsen sind braun. Die Flügel sind etwas verdunkelt, stärker verdunkelt längs des Costalrandes und in der Radialzelle, das Geäder ist dunkelbraun.

Kopf erheblich breiter als der Thorax, Netzaugen unten so stark genähert, dafs eben noch Platz für die Fühler bleibt, Clypeus um ein Vielfaches breiter als lang, dicht mit silbernem, von der Seite gesehen, rötlichem Toment bekleidet, in der Mitte ein deutlicher, aber kleiner, spitzer Höcker. Ocellen in einem stumpfen Dreieck; Abstand der hinteren Ocellen voneinander erheblich geringer als von den Netzaugen, ihr Abstand vom Hinterrande des Kopfes jedoch noch erheblich gröfser als der zwischen ihnen und den Netzaugen. Kopf im allgemeinen mälsig grob, ziemlich dicht punktiert, die spärliche Behaarung schimmert je nach dem Gesichtswinkel weifslich, gelblich oder rötlich; nur längs der inneren Augenränder ist sie ausgesprochen goldschimmernd.

Die Glieder der Fühlergeifsel sind kurz, breiter als lang mit Ausnahme der gestreckten beiden Basalglieder.

Die Punktierung des Thorax ist äufserst grob und kräftig, dabei auf dem Mesonotum sehr, auf dem Scutellum weniger dicht. Die Basis des Mittelsegments weist eine Querreihe gröfserer Gruben auf, sonst ist es punktiert und ohne scharfe Kanten. Die Mesopleuren sind punktiert, die Metapleuren dicht und fein geriefelt.

Das Abdomen ist auf dem ersten Tergite grob und dicht, auf dem zweiten ziemlich grob, auf dem dritten mälsig grob und ziemlich dicht punktiert, auf den übrigen verschwindet die Punktierung fast ganz, tritt aber auf dem letzten wieder deutlich hervor; Pygidialplatte lang und spitz, konkav. Sternite im allgemeinen glatt und unpunktiert, nur je mit einer feinen Punktreihe vor den bräunlichen Apicalrändern, nur das zweite Sternit zeigt eine feine und zerstreute Punktierung. 


\section{$2 \mathrm{BHL}$ Biodiversity Heritage Library}

1914. "Beschreibung einer neuen Crabronide aus Paraguay." Deutsche entomologische Zeitschrift 1914, 624-624.

View This Item Online: https://www.biodiversitylibrary.org/item/103241

Permalink: https://www.biodiversitylibrary.org/partpdf/41320

\section{Holding Institution}

Harvard University, Museum of Comparative Zoology, Ernst Mayr Library

\section{Sponsored by}

Biodiversity Heritage Library

\section{Copyright \& Reuse}

Copyright Status: Public domain. The BHL considers that this work is no longer under copyright protection.

This document was created from content at the Biodiversity Heritage Library, the world's largest open access digital library for biodiversity literature and archives. Visit BHL at https://www.biodiversitylibrary.org. 